\title{
The nitric oxide regulated nor promoter of Paracoccus denitrificans
}

\author{
Matthew I. Hutchings and Stephen Spiro
}

School of Biological Sciences, University of East Anglia, Norwich NR4 7TJ, UK

\author{
Author for correspondence: Stephen Spiro. Tel: +44 1603 593222. Fax: +44 1603592250. \\ e-mail: s.spiro@uea.ac.uk
}

\begin{abstract}
The promoter of the Paracoccus denitrificans nitric oxide reductase operon (norCBQDEF) has been characterized by primer extension and deletion analysis. A major transcript that is detectable only in anaerobically grown cells initiates 43.5 bp downstream of the centre of a putative binding site for the transcription factor NNR (nitrite and nitric oxide reductase regulator, which is known to regulate nor expression). A minor transcript initiates 121 bp upstream of the major transcript and is detectable in cells grown aerobically or anaerobically. Deletion derivatives of the nor promoter region were constructed and analysed in vivo using transcriptional fusions to the reporter gene lacz. Expression patterns from promoter deletions in a wild-type strain and an nnr mutant confirmed that the minor transcript is NNR independent, and makes a small contribution to nor expression under both aerobic and anaerobic growth conditions. A deletion derivative truncated to within 7 bp of the putative NNR-binding site showed a near wild-type response to anaerobic growth, showing that no upstream DNA sequences are required for activation of the major promoter. Site-directed mutagenesis of the putative NNR-binding site confirmed that this is the major cis-acting sequence mediating the anaerobic inducibility of nor expression.
\end{abstract}

Keywords: Paracoccus denitrificans, nitric oxide, transcription, denitrification

\section{INTRODUCTION}

In denitrifying bacteria growing in the absence of oxygen and in the presence of nitrate or nitrite, nitric oxide (NO) is produced by a nitrite reductase (of the copper or cytochrome $c d_{1}$ type), and is subsequently consumed by a nitric oxide reductase (Zumft, 1997; Watmough et al., 1999). In those organisms that have been studied, expression of the nitrite and NO reductase genes is coordinately regulated by a transcription factor belonging to the FNR (fumarate and nitrate reductase regulator)/CRP (cAMP receptor protein) family (Tosques et al., 1996; Arai et al., 1995; van Spanning et al., 1997; Vollack et al., 1999). In Rhodobacter sphaeroides and Paracoccus denitrificans, there is good evidence that the transcription factor (designated NnrR or NNR, respectively) is activated by NO or a chemical species related to NO (Kwiatkowski \& Shapleigh, 1996; Tosques et al., 1996; van Spanning et al., 1995, 1999).

Abbreviations: FNR, fumarate and nitrate reductase regulator; NNR, nitrite and nitric oxide reductase regulator; NO, nitric oxide.
The coordinate regulation by NO of the genes encoding the enzymes responsible for making and consuming NO may be a strategy for maintaining a low intracellular concentration of the toxic NO.

In $P$. denitrificans, NO reductase is encoded in the sixgene norCBQDEF operon, which has a predicted NNR (nitrite and nitric oxide reductase regulator)-binding site upstream of norC (de Boer et al., 1996; Fig. 1). The norC and nor $B$ genes encode the enzymically active NorCB complex that can be purified from $P$. denitrificans (de Boer et al., 1996; Hendriks et al., 1998). The remaining four genes have unknown functions, but are required for the synthesis of an active NO reductase in vivo (de Boer et al., 1996). Transcription of the nor genes is activated by NNR under anaerobic growth conditions in response to NO or a related species (van Spanning et al., 1995, 1999). NNR also activates the transcription of the divergent nirI and nirS genes that are required for nitrite reductase activity (Saunders et al., 1999). Another FNR family member, FnrP, activates expression of nitrate reductase in $P$. denitrificans, probably in response to anoxia and/or a redox signal (van Spanning et al., 
1997). NNR and FnrP appear to bind to identical or very similar DNA sequences, yet activate their target genes specifically with little or no cross-talk (van Spanning et al., 1997). FnrP appears to be a true orthologue of FNR, in that it contains the cysteine residues that are conserved in FNR-like proteins and are believed to provide ligands to an oxygen/redox-sensitive iron-sulphur cluster. NNR, on the other hand, does not have these residues and so is thought to function by a different mechanism (Baker et al., 1998).

As part of an effort aimed at understanding NOregulated gene expression in $P$. denitrificans, the promoter region of the NO reductase operon (nor) has now been studied and this paper reports the presence of two transcription-start sites. The major start site is active only in cultures grown anaerobically (with nitrate) and is positioned 43.5 bp downstream of the putative NNRbinding site, making this a class II (Busby \& Ebright, 1999) factor-dependent promoter (as is also the case for the nirI and nirS promoters; Saunders et al., 1999). In vivo analysis of deletion derivatives of the promoter, and of point mutations in the putative factor-binding site, has confirmed the location of the NNR-binding site and shown that NNR is the only regulatory protein with a significant role in controlling expression of the NO reductase.

\section{METHODS}

Bacterial strains, plasmids and growth media. The plasmids used were pUC18 for routine cloning (Yannisch-Perron et al., 1985) and the broad-host-range promoter probe vector, pMP220 (Spaink et al., 1987). Escherichia coli strain JM83 [ara $\Delta$ (lac-proAB) rpsL $\phi 80$ lacZ $\Delta \mathrm{M} 15]$ was used for all routine DNA manipulations, and S17-1 (thi pro hsdR recA integrated RP4-2 Tc::Mu Km::Tn7) was used as the donor for conjugations with $P$. denitrificans. The $P$. denitrificans strains used were Pd1222 (de Vries et al., 1989) and its isogenic nnr mutant Pd 77.71 (van Spanning et al., 1995). E. coli strains were grown in Lennox (L) broth and $P$. denitrificans strains were grown in a defined medium containing succinate as the sole carbon and energy source (Harms et al., 1985) and supplemented with $50 \mathrm{mM}$ nitrate for anaerobic growth. Antibiotics were used at the following concentrations ( $\mu \mathrm{g}$ $\left.\mathrm{ml}^{-1}\right)$ : ampicillin, 100 ; tetracycline, $0 \cdot 5$ (P. denitrificans) or $12 \cdot 5$ (E. coli); spectinomycin, 25 . Aerobic cultures $(20 \mathrm{ml}$ in $250 \mathrm{ml}$ flasks) of $P$. denitrificans were shaken at 250 r.p.m.; anaerobic cultures were grown in standing bottles filled to the top, in both cases at $30^{\circ} \mathrm{C}$. $\beta$-Galactosidase was assayed in duplicate according to the method of Miller (1992) on at least three independently grown exponential-phase cultures. E. coli was made competent using $0 \cdot 1 \mathrm{M} \mathrm{CaCl}_{2}, 10 \%$ (v/v) glycerol and was transformed using the method of Pope \& Kent (1996). Plasmids were introduced into $P$. denitrificans by conjugation (Shearer et al., 1999).

Primer extensions. Total RNA was isolated from $P$. denitrificans using RNeasy spin columns (Qiagen) according to the manufacturer's instructions. RNA integrity was checked by agarose gel electrophoresis and concentrations were determined by measuring the absorbance at $260 \mathrm{~nm}$. RNA (10 or $20 \mu \mathrm{g}$ ) was added to a $1.5 \mathrm{ml}$ microfuge tube containing $10 \mu \mathrm{l} 10 \mathrm{mM}$ DTT, 0.1 M KCl, 4 mM Tris/HCl (pH 7.9), 40 units RNasin (Promega) and $0 \cdot 2$ pmol ${ }^{32} \mathrm{P}$-end-labelled primer RNA1 (5'-CGTAGATATGGCTGTGCACGGTCAATGCGC-3'). The tube was heated to $80^{\circ} \mathrm{C}$ for $5 \mathrm{~min}$, incubated at $30^{\circ} \mathrm{C}$ for $3 \mathrm{~h}$ and then cooled on ice. Then $4 \mu \mathrm{l} 5 \times$ MMLV reverse transcriptase buffer, $2 \mu \mathrm{l} d \mathrm{NTP}$ mix $(50 \mathrm{mM}), 2 \mu \mathrm{l}$ DTT $(0 \cdot 1 \mathrm{M}), 0 \cdot 5 \mu \mathrm{l}$ actinomycin D and 200 units MMLV reverse transcriptase were added and the volume made up to $20 \mu \mathrm{l}$ with water. The reaction was incubated at $37^{\circ} \mathrm{C}$ for $1 \mathrm{~h}$ and stopped by addition of $4 \mu \mathrm{l}$ Sequenase stop solution (Amersham-Pharmacia). Products $(5 \mu \mathrm{l})$ were separated on an $8 \%$ sequencing gel alongside a sequencing ladder generated using primer RNA1.

PCR methods. The nor promoter fragments (norP175, nor 133 , nor $\mathrm{P} 98$ and norP57) were generated using the reverse primer nor P1B (5'-CGGGCGTAGATATGGCTGTGCACG$\left.3^{\prime}\right)$ and either P175 (5'-TTTGCCTGATGCCGCCCAAGGCCGC-3'), P133 (5'-GTCTGCCGGGCTGCCGTATCGAGCT-3'), P98 (5'-CGCAGGACGCGGAATTTCCGGACA$\left.3^{\prime}\right)$ or P57 (5'-CCTTCACTTGACTTTCATCAATGAG-3'). Each reaction contained 25 ng template DNA (pEG8HI; van Spanning et al., 1997), $2 \mu \mathrm{l}$ each primer $(25 \mu \mathrm{M}), 5 \mu \mathrm{l}$ Pwo buffer $\left(\mathrm{MgCl}_{2}\right.$ included $), 1.5 \mu \mathrm{dNTP} \operatorname{mix}(50 \mathrm{mM}), 0.5 \mu \mathrm{P}$ Po $\left(5\right.$ units $\left.\mu \mathrm{l}^{-1}\right)$ in a total volume of $50 \mu \mathrm{l}$. Reaction conditions were: $94{ }^{\circ} \mathrm{C}$ for $5 \mathrm{~min}$, then 25 cycles of $94^{\circ} \mathrm{C}$ for $30 \mathrm{~s}, 65^{\circ} \mathrm{C}$ for $30 \mathrm{~s}, 72^{\circ} \mathrm{C}$ for $30 \mathrm{~s}$, followed by $72{ }^{\circ} \mathrm{C}$ for $5 \mathrm{~min}$. Products were separated on a $1.5 \%$ agarose gel, purified using a Qiaex Gel extraction kit (Qiagen) and ligated into SmaI-cut, phosphatase-treated pUC18 (Pharmacia). Ligation reactions were then used to transform competent JM83 and plated on L agar + X-Gal and ampicillin. The orientations of the inserts were determined by colony PCR and then by sequencing of both strands. Each fragment was excised with KpnI and XbaI and ligated into pMP220 cut with the same enzymes, to generate plasmids designated pnorP57, pnorP98, pnorP133, pnorP175 and pnorP133NN (see Fig. 1b). For colony PCR, white colonies were picked and transferred to a $0.2 \mathrm{ml}$ PCR tube (the toothpick was then used to inoculate $5 \mathrm{ml} \mathrm{L}$ broth + ampicillin). The tubes were microwaved at full power (1000 $\mathrm{W}$ ), with the lids open, for $1 \mathrm{~min}$. PCR mix contained (for eight reactions) $20 \mu \mathrm{l} \mathrm{Taq}$ buffer, $12 \mu \mathrm{l} \mathrm{dNTP} \operatorname{mix}(50 \mathrm{mM})$, $16 \mu \mathrm{l}$ each primer $(5 \mu \mathrm{M}), 6 \mu \mathrm{MgCl}_{2}(50 \mathrm{mM}), 1 \mu \mathrm{l} \mathrm{Taq}$ and $129 \mu \mathrm{H} \mathrm{H}_{2} \mathrm{O} ; 25 \mu \mathrm{l}$ was added to each tube. The cycling conditions were as described above and products were separated on a $1.5 \%$ agarose gel. The primers used were the pUC18 Universal primer and the appropriate promoterspecific forward primer (P57, P98, P123 or P175).

PCR mutagenesis. To incorporate single or double point mutations into the nor promoter, appropriate complementary primers were used in an amplification reaction with plasmid DNA as the template. The template DNA was removed by treatment with $D p n I$ (which digests only methylated DNA) and the remaining DNA was used to transform JM83. Each reaction mix contained: $25 \mathrm{ng}$ template DNA (the P133 promoter cloned in pUC18), $5 \mu \mathrm{l}$ Pwo buffer $\left(\mathrm{MgCl}_{2}\right.$ included), $1.5 \mu \mathrm{l}$ dNTP mix $(50 \mu \mathrm{M}), 4 \mu \mathrm{M}$ each primer (NN1, 5'TTGCCTTCACCTGACTTTCATCAGTGAGCGACTC-3' and NN2, 5'-GAGTCGCTCACTGCTGAAAGTCAGGTGAAGGCAA-3', or TT1, 5'-CGACTCACGCGCGCCGGACAGT-3' and TT2, 5'-ACTGTCCGGCGCGCGTGAGTCG-3'), $0 \cdot 5 \mu \mathrm{l} P w o$ (5 units $\mu \mathrm{l}^{-1}$ ), in a total volume of $50 \mu \mathrm{l}$. Reaction conditions were: $94^{\circ} \mathrm{C}$ for $5 \mathrm{~min}$, then 25 cycles of $94{ }^{\circ} \mathrm{C}$ for $30 \mathrm{~s}, 67^{\circ} \mathrm{C}$ for $30 \mathrm{~s}, 72^{\circ} \mathrm{C}$ for $10 \mathrm{~min}$, followed by $72{ }^{\circ} \mathrm{C}$ for $15 \mathrm{~min}$. The reaction mixtures were transferred to $1.5 \mathrm{ml}$ tubes and treated with 10 units $D p n \mathrm{I}$ for $30 \mathrm{~min}$ at $37^{\circ} \mathrm{C}$, then $72^{\circ} \mathrm{C}$ for $30 \mathrm{~min}$. After cooling on ice, each reaction was treated with 2 units T4 DNA ligase for $1 \mathrm{~h}$ and 
then used to transform competent JM83. Control reactions contained no primers. Mutant DNAs were sequenced using an ABI Prism automated sequencer. Other general recombinant DNA techniques were as described by Sambrook et al. (1989).

\section{RESULTS AND DISCUSSION}

\section{Transcript analysis of the nor promoter}

Primer extension analysis using total RNA isolated from nitrate respiring $P$. denitrificans $\mathrm{Pd} 1222$ consistently revealed the presence of two transcription-start sites (Fig. 1a). The apparently major transcript initiates at a site designated P1 downstream of the putative NNRbinding site. A second start site, P2, is upstream of the NNR-binding site and 121 bp upstream of P1 (Fig. 1b). The proposed NNR-binding site is centred $43.5 \mathrm{bp}$ upstream of P1. Primer-extension analysis with total RNA from aerobically grown cells detected only the P2 transcript, at a somewhat lower level than in anaerobically grown cells (Fig. 1a). The additional products seen in Fig. 1a, indicative of mRNAs apparently initiating between P1 and P2, were not seen consistently in all reactions and so are probably non-specific products resulting either from premature termination of the primer extension, or from non-specific annealing of the primer to another mRNA. Identification of the transcription-start sites of four NNR-dependent promoters from $P$. denitrificans and Paracoccus pantotrophus (this work; Saunders et al., 1999, 2000) allowed inspection of the sequences for possible promoter elements and cis-acting sequences. It has been suggested that NNR-regulated promoters may be targets for RNA polymerase containing an alternative sigma factor (Baker et al., 1998) or for regulation by additional transcription factor(s) (Saunders et al., 2000). The rationale behind these proposals comes from the fact that both FnrP and NNR are believed to recognize the same binding site at their target promoters in $P$. denitrificans yet activate their target genes specifically. The factor binding sites upstream of the FnrP-regulated $c c o N$ promoter and the NNR-regulated norC promoter of $P$. denitrificans have identical core-binding motifs,

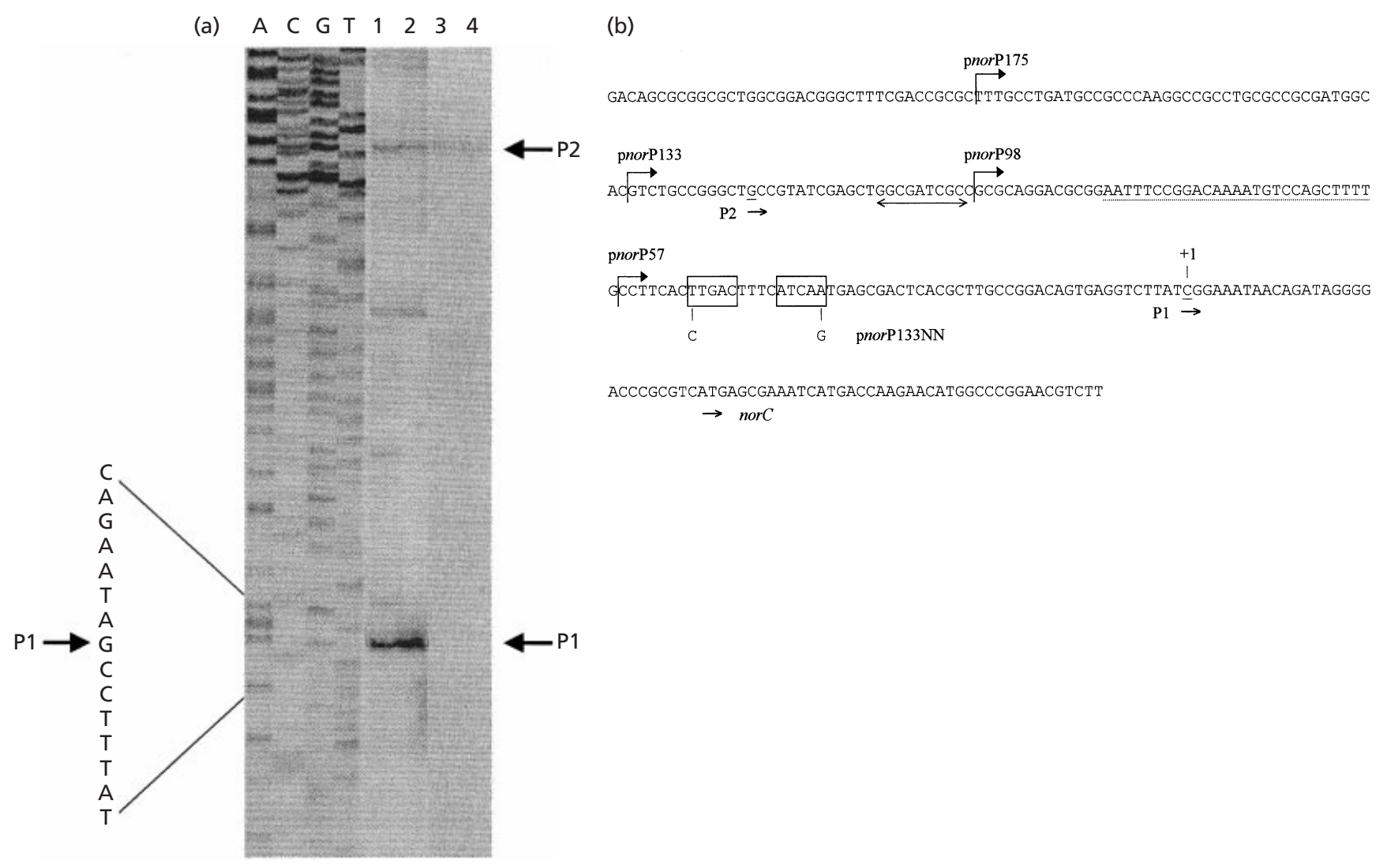

Fig. 1. (a) Primer-extension analysis using 10 (lanes 1 and 3) or $20 \mu \mathrm{g}$ (lanes 2 and 4 ) of total RNA isolated from anaerobic (lanes 1 and 2) and aerobic (lanes 3 and 4) cultures of $P$. denitrificans Pd1222. Reactions were run alongside a sequencing ladder generated using the same primer (RNA1). The major (P1) and minor (P2) transcripts are marked, and the sequence around $\mathrm{P} 1$ is highlighted. The nucleotide sequence around $\mathrm{P} 2$ was determined from a similar gel that was run further to separate the sequence ladder. (b) The norC promoter sequence with both transcript-start sites marked. The nucleotides at which transcription initiates are underlined. The putative NNR-binding site (TTGAC----ATCAA) is boxed, the AT-rich sequence is indicated with a dotted line and the $10 \mathrm{bp}$ palindrome is indicated with a double-headed arrow. The $5^{\prime}$ limits of the deletion derivatives are indicated, along with the names of the plasmids in which they were cloned. Plasmid numbers indicate the number of nucleotides upstream of P1 incorporated in the promoter-lacZ fusion. 


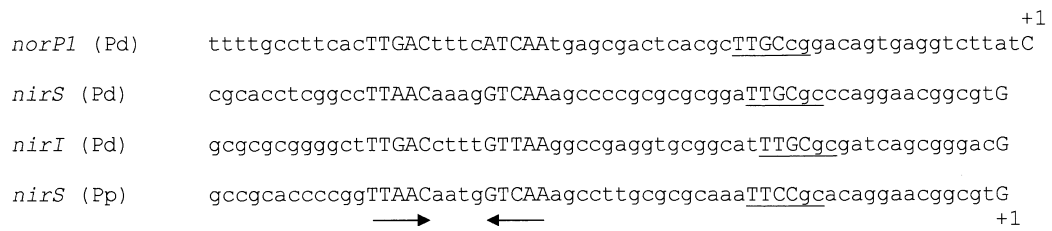

Fig. 2. Alignment of the three known NNRdependent promoters from $P$. denitrificans (Pd) from the norC, nirl and nirs genes. Note that nirl and nirs are divergently transcribed, with a single NNR-binding site in the intergenic region (Saunders et al., 1999). Also shown is the nirs promoter from P. pantotrophus ( $\mathrm{Pp}$; Saunders et al., 2000). Sequences are aligned at their NNR-binding sites and the conserved TTGC sequence is underlined. and yet there does not appear to be any cross-talk between the two regulators (van Spanning et al., 1997).

\section{Promoter alignments}

All four promoters appear to be class II, with the factorbinding site centred $41.5-43.5 \mathrm{bp}$ upstream of the transcription-start site, which is the preferred spacing for FNR-dependent promoters (Wing et al., 1995). Otherwise, the alignment of the nirl, nirS and norC promoters reveals very little similarity (Fig. 2). Only one sequence appears to be conserved, a TTGC motif positioned 14-20 bp upstream of each transcript start site, as recently noted by Saunders et al. (2000) for the nirS promoters of both $P$. pantotrophus and $P$. denitrificans. This sequence, and its position, are reminiscent of the conserved -12 recognition sequence for the alternative sigma factor, $\sigma^{\mathrm{N}}$ (Wang et al., 1999). However, the NNR-dependent promoters have only weak matches to the -24 element consensus, the second $\sigma^{\mathrm{N}}$ recognition element (Barrios et al., 1999), and so are unlikely to be dependent on RNA polymerase containing $\sigma^{\mathrm{N}}$. Neither is there any obvious similarity to the -10 and -35 recognition elements for the major ( $\sigma^{70}$ type) sigma factor found in many promoters from other bacteria, although it has been proposed that these motifs are likely to be conserved in the $\alpha$-Proteobacteria (Gruber \& Bryant, 1997; Baker et al., 1998). Hence, the role of the TTGC motif, if any, is uncertain and was tested by mutagenesis (see below).

Other interesting features of the nor promoter region include an AT-rich sequence positioned immediately upstream of the factor-binding site, and a $10 \mathrm{bp}$ palindrome further upstream (Fig. 1b). The AT-rich sequence $(67 \mathrm{~mol} \% \mathrm{~A}+\mathrm{T})$ is atypical for $P$. denitrificans DNA (23 mol \% A + T) and may represent an additional regulatory feature or promoter element. It is positioned where the C-terminal domains of the RNA polymerase $\alpha$ subunits would contact the DNA, according to the class II model of transcription activation (Busby \& Ebright, 1999). The $10 \mathrm{bp}$ palindrome is the only significant symmetrical sequence detected in the nor upstream region and is similar to a sequence found in the divergent nirI and nirS promoters (Saunders et al., 1999).

The transcript start site of the nor operon of Pseudomonas stutzeri has also been determined and is positioned $40.5 \mathrm{bp}$ downstream of a binding site for a regulatory protein of the FNR family (Zumft et al., 1994). Transcription initiation from this promoter is independent of $\sigma^{\mathrm{N}}$ (Härtig \& Zumft, 1998). At least in these respects, the nor promoters of Pse. stutzeri and Par. denitrificans appear to be similar.

\section{In vivo analysis of the nor promoter}

To investigate the nor $C$ promoter further, a series of $5^{\prime}$ deletions was constructed by PCR. Deletions were designed with the aim of identifying any regions of DNA that may be required for promoter activity and regulation. Each promoter fragment was cloned into the low-copy-number promoter-probe vector pMP220 and the resulting constructs were conjugated into $P$. denitrificans Pd1222. A Pd1222 derivative containing a singlecopy chromosomal norP-lacZ fusion (van Spanning et al., 1997) was used to check that there were no major copy-number effects associated with the use of pMP220. The largest promoter construct (in pnor P175) contains both the P1 and P2 start sites, with $54 \mathrm{bp}$ of DNA upstream of P2 (Fig. 1b). The second deletion (in pnorP133) contains P1 and is truncated immediately upstream of the P2 start site, having only 12 bp of DNA upstream of P2. This deletion was designed to remove the RNA polymerase-binding site presumably associated with P2. Subsequent truncations removed the palindrome (pnorP98) and the AT-rich sequence (pnorP57) in turn (Fig. 1b). The full-length plasmid-borne construct (pnorP175) exhibited only approximately twofold higher activity than the chromosomal-borne, singlecopy fusion and was regulated in a similar fashion (Fig. $3)$. In both cases there is a substantial increase in promoter activity in cultures grown under anaerobic, denitrifying conditions. Removal of the sequences immediately upstream of P2 (pnorP133) had a relatively small effect, but caused a greater decrease in nor promoter activity under anaerobic conditions than under aerobic conditions (Fig. 3). This suggests that the P2 transcript makes a small contribution to the total nor promoter activity, which is more significant under anaerobic conditions; this conclusion is consistent with the results of the mRNA analysis. Removal of the $10 \mathrm{bp}$ palindrome (in pnorP98) had no significant effect on nor promoter activity. Removal of the AT-rich sequence (in pnorP57) caused a further small decrease in the aerobic activity of the promoter, and a small increase in 


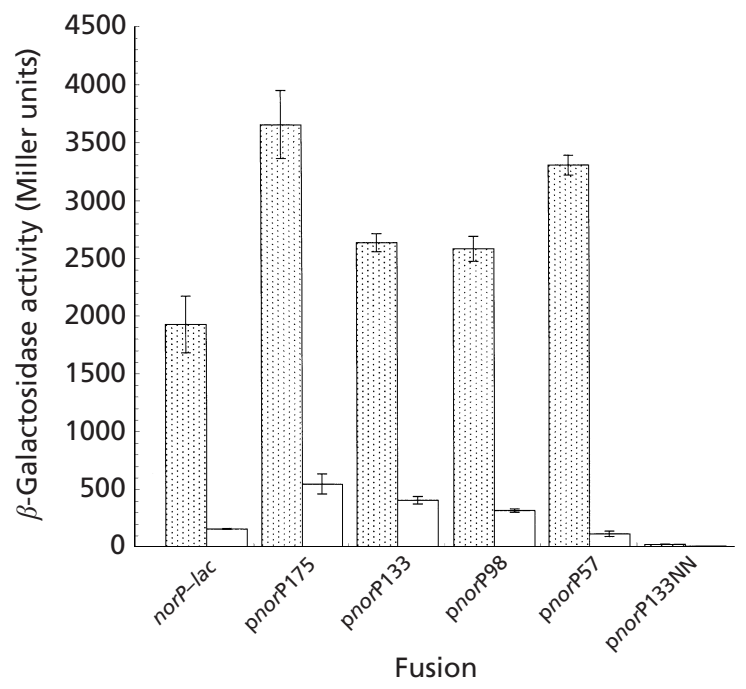

Fig. 3. Histogram showing $\beta$-galactosidase activities for each nor promoter-lacZ fusion. Plasmid pnorP133NN is identical to plasmid pnorP133 except for an altered (NN) NNR-binding site. Anaerobic cultures are represented by spotted bars; aerobic cultures are represented by white bars.

anaerobic activity, compared to the previous two deletions (Fig. 3). This suggests that the AT-rich sequence may have a negative effect on transcription from nor $\mathrm{P} 1$. The pnor $\mathrm{P} 57$ construct contains a promoter deleted to within 7 bp of the putative NNR-binding site, yet retains the anaerobic inducibility of the full-length nor promoter. Thus, the P1 promoter is the most important contributor to the activation of the nor promoter, which presumably occurs through NNR binding to the putative binding site retained in pnorP57.

The small contribution of $\mathrm{P} 2$ to the nor promoter was confirmed by conjugating pnorP175 and pnorP133 into an $n n r$ mutant, Pd77.71 (van Spanning et al., 1999). In anaerobic cultures (which in the case of this strain grow very poorly), 270 units of $\beta$-galactosidase activity were recorded for Pd77.71 (pnorP175) while Pd77.71 (pnorP133) had only 70 units of activity. This confirms that the nor $\mathrm{P} 2$ is NNR independent, and makes only a small contribution to nor promoter activity under anaerobic conditions. In aerobic cultures of the NNR mutant, pnorP175 and pnorP133 directed similarly low $\beta$-galactosidase activities (90 and 70 units respectively).

The high anaerobic activity of the shortest promoter construct (pnorP57) is not consistent with norP1 being dependent on $\sigma^{\mathrm{N}}$, since in all known cases $\sigma^{\mathrm{N}}$ has an absolute requirement for an additional transcription factor (upstream activator) bound to a remote site $100 \mathrm{bp}$ or more upstream of the transcript start (Shingler, 1996). This conclusion was further supported by the finding that alteration of the TTGC motif to TTTT had no significant effect on nor promoter activity in the full-length construct (results not shown). Thus, nor $\mathrm{P} 1$ cannot be $\sigma^{\mathrm{N}}$ dependent, since at $\sigma^{\mathrm{N}}$-dependent promoters the GC nucleotides of the -12 element are essential for promoter activity (Barrios et al., 1999). Mutation of the TTGC motif to GCGC resulted in a $20 \%$ reduction in promoter activity anaerobically, demonstrating that this motif, though conserved at a similar position at all four NNR-dependent promoters, is not essential for promoter activation (results not shown).

To show unequivocally that the suggested NNR-binding site does indeed play this role, the sequence (TTGACtttcATCAA) was altered to the neutral NN sequence (CTGACtttcATCAG), which is recognized by neither FNR nor CRP of E. coli (Spiro et al., 1990), and which it was assumed would not be recognized by NNR. Mutagenesis was undertaken on the promoter fragment containing only 12 bp of DNA upstream of P2 (Fig. 1a) since in the fusion vector containing this fragment (pnorP133) only $\mathrm{P} 1$ is active anaerobically (Fig. 3). Introduction of the $\mathrm{NN}$ sequence into the putative NNR-binding site (in pnorP133NN) eliminated promoter activity under anaerobic conditions and abolished the residual aerobic activity seen in pnorP57 (Fig. 3). Hence, nor 1 activity is completely dependent on the putative NNR-binding site and it is very likely that NNR recognizes the same sequence, or a very similar sequence, as does E. coli FNR. These results also suggest that at least some of the nor promoter activity in aerobic cultures depends on NNR, indicating that there may be some active NNR present in aerobic cells. Attempts to confirm the NNR-DNA interaction biochemically using purified protein in gel-retardation assays (in the presence and absence of $\mathrm{NO}$ generators) have so far proved inconclusive.

\section{Concluding remarks}

The physiological role of the minor NNR-independent promoter of the nor operon is unclear. Transcription from this promoter was detected both aerobically and anaerobically, in vivo and in vitro, and is consistent with previous reports of a low level of activity of the nor promoter in aerobic cultures (van Spanning et al., 1999). Furthermore, there is substantial residual NOR activity in an $n n r$ mutant, and the NorC polypeptide is detectable in aerobically grown cells (van Spanning et al., 1997). All of these observations point towards there being a significant NNR-independent activity of the nor promoter under both aerobic and anaerobic conditions. Aerobic expression of NO reductase may safeguard cells against sudden exposure to $\mathrm{NO}$, and may have a role in the reported ability of $P$. denitrificans to denitrify in the presence of oxygen (Davies et al., 1989). However, the low level of aerobic activity observed with the chromosomal fusion strain and with the plasmid-borne fusions was reduced but not completely abolished by removal of norP2 and must therefore be partly due to norP1. Mutation of the NNR-binding site completely abolished both anaerobic and aerobic activity of nor 1 1, which suggests that at least some of the activity detected aerobically is NNR dependent. The key to understand- 
ing NO signalling and NNR-dependent regulation in $P$. denitrificans lies in identifying the sigma factor(s) which recognize NNR-dependent promoters and on elucidating the exact mechanism of NNR activation by NO.

\section{ACKNOWLEDGEMENTS}

We thank Rob van Spanning for generously providing strains, Neil Shearer and Ray Dixon for useful discussions and Wendy Leung for help in collecting the $\beta$-galactosidase data. This work was supported by a BBSRC grant.

\section{REFERENCES}

Arai, H., Igarashi, Y. \& Kodama, T. (1995). Expression of the nir and nor genes for denitrification of Pseudomonas aeruginosa requires a novel CRP/FNR-related transcriptional regulator, DNR, in addition to ANR. FEBS Lett 371, 73-76.

Baker, S. C., Ferguson, S. J., Ludwig, B., Page, M. D., Richter, O. M. H. \& van Spanning, R. J. M. (1998). Molecular genetics of the genus Paracoccus: metabolically versatile bacteria with bioenergetic flexibility. Microbiol Mol Biol Rev 62, 1046-1078.

Barrios, H., Valderamma, B. \& Morett, E. (1999). Compilation and analysis of $\sigma^{54}$-dependent promoter sequences. Nucleic Acids Res 27, 4305-4313.

de Boer, A.P. N., van der Oost, J., Reijnders, W. N. M., Westerhoff, H. V., Stouthamer, A. H. \& van Spanning, R. J. M. (1996). Mutational analysis of the nor gene cluster which encodes nitric oxide reductase in Paracoccus denitrificans. Eur J Biochem 242, 592-600.

Busby, S. \& Ebright, R. H. (1999). Transcription activation by catabolite activator protein (CAP). J Mol Biol 293, 199-213.

Davies, K. J. P., Lloyd, D. \& Boddy, L. (1989). The effect of oxygen on denitrification in Paracoccus denitrificans and Pseudomonas aeruginosa. J Gen Microbiol 135, 2445-2451.

Gruber, T. M. \& Bryant, D. A. (1997). Molecular systematic studies of Eubacteria, using $\sigma^{70}$-type sigma factors of group 1 and group 2. J Bacteriol 179, 1734-1747.

Harms, N., de Vries, G. E., Maurer, K., Veltkamp, E. \& Stouthamer, A. H. (1985). Isolation and characterization of Paracoccus denitrificans mutants with defects in the metabolism of one-carbon compounds. J Bacteriol 164, 1064-1070.

Härtig, E. \& Zumft, W. G. (1998). The requirement of RpoN (sigma factor $\sigma^{54}$ ) in denitrification by Pseudomonas stutzeri is indirect and restricted to the reduction of nitrite and nitric oxide. Appl Environ Microbiol 64, 3092-3095.

Hendriks, J., Warne, A., Gohlke, U., Haltia, T., Ludovici, C., Lübben, M. \& Saraste, M. (1998). The active site of the bacterial nitric oxide reductase is a dinuclear iron centre. Biochemistry 37 , 13102-13109.

Kwiatkowski, A. V. \& Shapleigh, J. P. (1996). Requirement of nitric oxide for induction of genes whose products are involved in nitric oxide metabolism in Rhodobacter sphaeroides 2.4.3. J Biol Chem 271, 24382-24388.

Miller, J. H. (1992). A Short Course in Bacterial Genetics. Cold Spring Harbor, NY: Cold Spring Harbor Laboratory.

Pope, B. \& Kent, M. H. (1996). High efficiency 5-minute transformation of Escherichia coli. Nucleic Acids Res 24, 536-537.

Sambrook, J., Fritsch, E. F. \& Maniatis, T. (1989). Molecular Cloning: a Laboratory Manual, 2nd edn. Cold Spring Harbor, NY: Cold Spring Harbor Laboratory.

Saunders, N. F. W., Houben, E. N. G., Koefoed, S., de Weert, S., Reijnders, W. N. M., Westerhoff, H. V., De Boer, A. P. N. \& van
Spanning, R. J. M. (1999). Transcription regulation of the nir gene cluster encoding nitrite reductase of Paracoccus denitrificans involves NNR and NirI, a novel type of membrane protein. Mol Microbiol 34, 24-36.

Saunders, N. F. W., Ferguson, S. J. \& Baker, S. C. (2000). Transcriptional analysis of the nirS gene, encoding cytochrome $c d_{1}$ nitrite reductase, of Paracoccus pantotrophus LMD 92.63. Microbiology 146, 509-516.

Shearer, N., Hinsley, A. P., van Spanning, R. J. M. \& Spiro, S. (1999). Anaerobic growth of Paracoccus denitrificans requires cobalamin: characterization of cobK and cobJ genes. J Bacteriol 181, 6907-6913.

Shingler, V. (1996). Signal sensing by $\sigma^{54}$-dependent regulators: derepression as a control mechanism. Mol Microbiol 19, 409-416.

Spaink, H. P., Okker, J. H., Wijffelman, C. A., Pees, E. \& Lugtenberg, B. J. J. (1987). Promoters in the nodulation region of the Rhizobium leguminosarum Sym plasmid pRL1JL. Plant Mol Biol 9, 27-39.

van Spanning, R. J. M., de Boer, A.P. N., Reijnders, W. N. M., Spiro, S., Westerhoff, H. V., Stouthamer, A. H. \& van der Oost, J. (1995). Nitrite and nitric oxide reduction in Paracoccus denitrificans is under the control of NNR, a regulatory protein that belongs to the FNR family of transcriptional regulators. FEBS Lett 360, 151-154.

van Spanning, R. J. M., de Boer, A. P. N., Reijnders, W. N. M., Westerhoff, H. V. \& van der Oost, J. (1997). FnrP and NNR of Paracoccus denitrificans are both members of the FNR family of transcriptional activators but have distinct roles in respiratory adaptation in response to oxygen limitation. Mol Microbiol 23, 893-907.

van Spanning, R. J. M., Houben, E., Reijnders, W. N. M., Spiro, S., Westerhoff, H. V. \& Saunders, N. (1999). Nitric oxide is a signal for NNR-mediated transcription activation in Paracoccus denitrificans. J Bacteriol 181, 4129-4132.

Spiro, S., Gaston, K. L., Bell, A. I., Roberts, R. E., Busby, S. J. W. \& Guest, J. R. (1990). Interconversion of the DNA binding specificities of two related transcription regulators, CRP and FNR. Mol Microbiol 4, 1831-1838.

Tosques, I. E., Shi, J. \& Shapleigh, J. P. (1996). Cloning and characterization of $n n r R$, whose product is required for the expression of proteins involved in nitric oxide metabolism in Rhodobacter sphaeroides 2.4.3. J Bacteriol 178, 4958-4964.

Vollack, K. U., Hartig, E., Korner, H. \& Zumft, W. G. (1999). Multiple transcription factors of the FNR family in denitrifying Pseudomonas stutzeri: characterisation of four fnr-like genes, regulatory responses and cognate metabolic processes. Mol Microbiol 31, 1681-1694.

de Vries, G. E., Harms, N., Hoogendijk, J. \& Stouthamer, A. H. (1989). Isolation and characterization of Paracoccus denitrificans mutants with increased conjugation frequencies and pleiotropic loss of a (nGATCn)-DNA-modifying property. Arch Microbiol 152, 52-57.

Wang, L., Guo, Y. \& Gralla, J. D. (1999). Regulation of sigma 54dependent transcription by core promoter sequences : role of -12 region nucleotides. J Bacteriol 181, 7558-7565.

Watmough, N. J., Butland, G., Cheesman, M. R., Moir, J. W. B., Richardson, D. J. \& Spiro, S. (1999). Nitric oxide in bacteria: synthesis and consumption. Biochim Biophys Acta 1411, 456-474.

Wing, H. J., Williams, S. M. \& Busby, S. J. W. (1995). Spacing requirements for transcription activation by Escherichia coli FNR protein. J Bacteriol 177, 6704-6710.

Yanisch-Perron, C., Vieira, J. \& Messing, J. (1985). Improved M13 
phage cloning vectors and host strains: nucleotide sequences of M13mp18 and pUC19 vectors. Gene 33, 103-119.

Zumft, W. G. (1997). Cell biology and molecular basis of denitrification. Microbiol Mol Biol Rev 61, 253-264.

Zumft, W. G., Braun, C. \& Cuypers, H. (1994). Nitric oxide reductase from Pseudomonas stutzeri. Primary structure and gene organization of a novel bacterial cytochrome $b c$ complex. Eur J Biochem 219, 481-490.

Received 28 April 2000; revised 6 July 2000; accepted 12 July 2000. 